\title{
Synthesis of a Polydispersed Polybutadiene Latex. Direct Method for High-Solid Polybutadiene Emulsion Preparation
}

\author{
Yoshihiko ARAKI \\ Central Technical Research Laboratory, Nippon Oil Co., Ltd., \\ Yokohama 231, Japan
}

(Received June 2, 1986)

\begin{abstract}
A high solid, polydispersed polybutadiene latex of large particle size was synthesized. The reaction was carried out at a high monomer/water ratio and a small quantity of emulsifier (soap). Additions of a colloidally active material with a high molecular weight and an electrolyte were effective in limiting the surface film of growing polymer particles governed by water structure or ionic environment and, also, in promoting the agglomeration of particles. A mixture of sodium alginate and magnesium sulfate was particularly effective, and provided a method with excellent reproducibility.
\end{abstract}

KEY WORDS Acrylonitrile-Butadiene-Styrene Resin / Polybutadiene Latex / High-Solid Latex / Polydispersed Latex /

Acrylonitrile-butadiene-styrene (ABS) resin is a 3-component type thermoplastic resin formed from acrylonitrile (AN), butadiene (BD), and styrene (ST). Due to its high impact resistance, toughness and excellent molding characteristics, it finds wide application as a universal engineering plastic for the automobile, household electric appliance, building material industries and etc. Many manufacturing processes are developed according to these applications. ${ }^{1}$ In general, AN and ST are grafted by emulsion polymerization onto polybutadiene latex. From the viewpoint of its intended use, it is demanded that the base material, polybutadiene latex, have large particle size and be polydispersed. ${ }^{2-4}$

Various methods have been proposed in order to obtain a large particle polydispersed latex. ${ }^{5}$ The most common one is an emulsion polymerization wherein the monomer/water ratio is large and the quantity of the emulsifier should be small, and polymer particles are made to coalesce during the course of polymerization to form larger ones. ${ }^{6,7}$ This is achieved by putting the polymer particles just before the critical condition in which an unstable system containing considerable prefloc and coalescing of particles occurs.

In such a direct, high concentration polymerization with a high monomer/water ratio, the reaction enters a thickening stage ${ }^{8}$ early on, that is, $20-30 \%$ conversion, and the stirring becomes difficult. At this moment, particles are clustered and become most compact. If the polymerization is continued, it goes out of control. On account of the small quantity of the emulsifier, the soap coverage ${ }^{9}$ of the particles decreases. This decreases the mechanical stability of the particles and promotes their coalescence. Careful stirring is necessary to remove the heat of polymerization evolved at this high viscous stage and to promote agglomeration, causing the reduction of viscosity and increase of soap coverage to stabilize the system.

A method like this suffers from the disadvantage that a precise reaction-controlling technique is required to prevent excessive 
coagulation. Howland et al.,${ }^{10}$ obtained a low viscosity and high solid latex by concentration of a low solid latex by adding $0.03-0.04$ parts PVME (polyvinyl methyl ether). They pointed out that the addition of PVME and some electrolytes moderates the hydration of the particle surface and eliminates the surface film, so that particle coalescence proceeds well during the concentrating procedure.

In the present study, the effects of colloidery active materials such as gelatin, CMC (carboxymethyl cellulose) and sodium alginate in addition to PVME in combination with some electrolytes on the high solid polymerization were investigated. An advanced method to obtain a high solid, polydispersed polybutadiene latex having $0.1-1 \mu \mathrm{m}$ size and lower viscosity using two or three additives to promote the particle agglomeration during the course of growth is reported.

\section{EXPERIMENTAL}

\section{Monomer and Reagents}

The following materials were used: butadiene (Nippon Petrochemicals Co., Ltd., 98.5\% up), sodium rosinate (Toho Chemical Industry Co., Ltd. (DIPRODIN Na-15)), fatty acid soap (Kao Corporation (OS SOAP)), potassium persulfate (analytical grade, $98.0 \%$ up), n-dodecyl mercaptan (Kao Corporation (THIOKALCOL, 95\% up)) and sodium alginate (Kamogawa Chemicals Co., Ltd. (DUCKALGIN, \#NPSL, the viscosity of $1 \%$ aq. solution is $100 \mathrm{CP}$ )).

\section{Analysis}

Extent of Polymerization. Approx. $1 \mathrm{~g}$ of aliquot was transferred to an aluminum dish and weighed. The total solid content in the aliquot was determined by evaporating the water and monomer under reduced pressure in a vacuum oven at $120^{\circ} \mathrm{C}$ and conversion was calculated.

Particle Size Distribution. Particle size distribution was determined by electron micro- scope $^{11}$ and the alginate creaming method. ${ }^{12}$ The reference sample for the electron microscope was a Dow monodispersed polystyrene latex (LS-1047-E, $d=0.234 \pm 0.0026$ ).

Gel Content and Swelling Index. The polymer sample was immersed in benzene and left in a dark place for $24 \mathrm{~h}$. The gel content and swelling index were then determined by the usual methods.

Viscosity. A Brookfield rotating viscometer was used.

\section{Polymerization}

The appropriate amounts of water, emulsifier, mercaptan and agglomeration promoters consisting of sodium alginate and $\mathrm{MgSO}_{4}$ were introduced into a glass-lined autoclave provided with a sightwindow and mechanical stirrer with Brumagin-type turbin blades. ${ }^{13,14}$ After replacing the air in the vessel with nitrogen, the pressure was reduced, and butadiene was charged. The vessel was then heated with stirring and, when the temperature reached the specified value, an aqueous solution of potassium persulfate was pressureinjected to start the polymerization. During polymerization, the reaction temperature was further raised, then booster solution ${ }^{15}$ (consisting of emulsifier, mercaptan and aqueous solution of potassium persulfate) and another emulsifier solution were added. After $60-70 \mathrm{~h}$, the conversion reached over $95 \%$.

The following is the most typical procedure for synthesis. Monomer/water ratio is $100 / 52$, 1 part of emulsifier (sodium rosinate) being added, and polymerization is started at 46 or $52^{\circ} \mathrm{C}$. Sampling is carried out at $1 \mathrm{~h}$ intervals, the total solids in the samples are measured and the conversion is calculated. When the conversion attains $10 \%$, the temperature is raised to $52^{\circ} \mathrm{C}$ in case of $46^{\circ} \mathrm{C}$ start, and when it reaches $40 \%$, the temperature is raised to $66^{\circ} \mathrm{C}$. An additional emulsifier is induced as a stabilizer at a conversion range from 50 to $70 \%$, to prevent excessive coagulation; the above booster solution is added at $60 \%$ con- 
version to generate new particles and compensate for the decreased rate of polymerization due to the decrease of particles.

After the polymerization, the reaction mixture is cooled and unreacted butadiene is removed. Total amounts of solids, viscosity and particle size distribution in the latex obtained are measured. A polydispersed latex with a large particle size on the average remains at a practical viscosity until the total solid content approaches a high solid, 60$70 \%$. The viscosity of the latex can be a quick guide to particle size and polydispersibility. ${ }^{16}$ In addition, part of the latex is evaporated to dryness, and the gel content and swelling index of the polymer were determined.

\section{RESULTS AND DISCUSSION}

\section{The Effect of the Addition of Electrolytes}

Figure 1 shows typical time-conversion curves for some systems. The addition of some electrolytes in the emulsion polymerization induces the reduction of viscosity at the thickening stage and may contribute to coalescence of the polymer particles. Table I shows the results of the polymerization with the addition of $0.1-0.5$ parts $\mathrm{KCl}$ and $\mathrm{Na}_{2} \mathrm{SO}_{4}$ to 100 parts monomer to control the process of the high-solid polymerization and shows also that highly viscous latices were obtained without electrolyte, while the addition of $\mathrm{KCl}$ or $\mathrm{Na}_{2} \mathrm{SO}_{4}$ promoted agglomeration and decreased the viscosity, but showed less reproducibility. This tendency is increased with the amounts of additives.

\section{Effects of the Addition of High Molecular \\ Weight, Colloidally Active Materials}

The effects of the addition of colloidally active materials such as gelatin, CMC (carboxymethyl cellulose), PVME and sodium alginate on the high-solid polymerization were investigated. The addition of the colloidally active materials lead to the preferential formation of coagulum or destruction of the

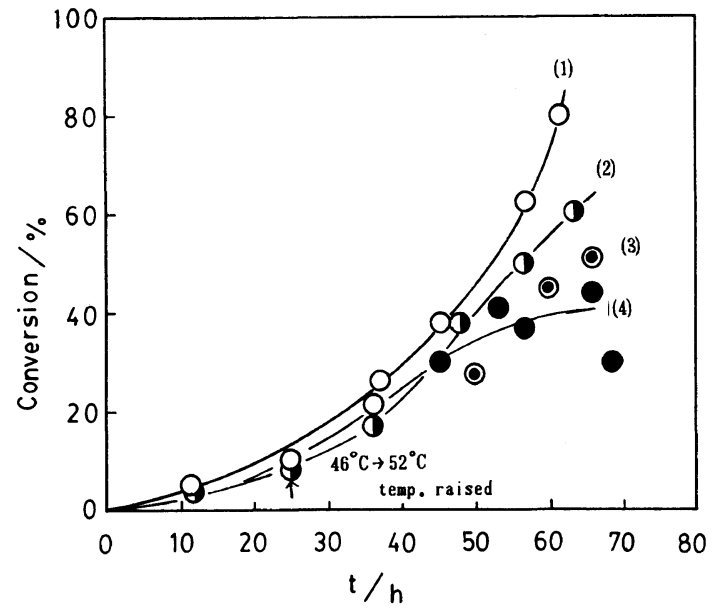

Figure 1. Time-conversion curves in the case of $\mathrm{KCl}$ addition. Butadiene, $100 \mathrm{~g}$; water, $52 \mathrm{~g}$; Na-rosinate, $1 \mathrm{~g}$; KPS, $0.3 \mathrm{~g} ; n$-DDM, $0.25 \mathrm{~g}$; temp $=46^{\circ} \mathrm{C}, 52^{\circ} \mathrm{C}, 66^{\circ} \mathrm{C}$; additive, $\mathrm{KCl}$; (1) $\bigcirc$, none; (2) $\bigcirc, 0.2 \mathrm{phr}$; (3) $\odot$, $0.5 \mathrm{phr}$; (4) $0.5 \mathrm{phr}$.

emulsion system as shown in Table II. This result is different from Howlands' work. ${ }^{10}$

\section{Concurrent Use of High Molecular Weight Materials and Electrolytes for High Solid Polymerization}

High solid polymerizations with combined additives, i.e., $\mathrm{CMC}-\mathrm{KCl}, \mathrm{CMC}-\mathrm{MgSO}_{4}$, $\mathrm{PVME}-\mathrm{MgSO}_{4}$, sodium alginate- $\mathrm{KCl}$, sodium alginate- $\mathrm{ZnSO}_{4}$ and sodium alginate$\mathrm{Al}_{2}\left(\mathrm{SO}_{4}\right)_{3}$ were carried out. In all cases, a large quantity of coagulated or paste polymer formed. Table II shows a comparison of the effects on the particle agglomeration for the PVME system and PVME- $\mathrm{MgSO}_{4}$ one, as an example. The high molecular weight, colloidally active material apparently has an effect on the coalescence of the particles and this tendency increased with the amount of electrolyte, even if only slight. As for reproducibility, polymerization systems other than sodium alginate- $\mathrm{MgSO}_{4}$ were not appropriate, and also impossible to avoid coagulation due to partial destruction of the emulsion. 
Table I. Effects of the addition of $\mathrm{KCl}$ and $\mathrm{Na}_{2} \mathrm{SO}_{4}$ on the high solid polymerization ${ }^{\mathrm{a}}$

\begin{tabular}{|c|c|c|c|c|c|c|}
\hline \multicolumn{2}{|c|}{ Electrolyte } & \multirow{4}{*}{$\frac{\text { Temp }}{{ }^{\circ} \mathrm{C}}$} & \multirow{4}{*}{$\frac{\text { Time }}{\mathrm{h}}$} & \multirow{4}{*}{$\frac{\text { Conversion }}{\%}$} & \multirow{4}{*}{$\frac{\text { Total solid }}{\%}$} & \multirow{4}{*}{$\frac{\text { Viscosity }}{\mathrm{CP}}$} \\
\hline $\mathrm{KCl}$ & $\mathrm{Na} \mathrm{SO}$ & & & & & \\
\hline net & $\mathrm{CO}_{2} \mathrm{NO}_{4}$ & & & & & \\
\hline $\mathrm{phr}$ & $\mathrm{phr}$ & & & & & \\
\hline - & - & $44-66$ & 70 & 78.6 & 57.4 & 859 \\
\hline- & - & $44-66$ & 72 & Coagulate & - & - \\
\hline - & - & $44-66$ & 71 & 83.0 & 59.1 & 394 \\
\hline 0.1 & - & $52-66$ & 70 & 84.2 & 54.7 & 320 \\
\hline 0.1 & - & $46-66$ & 70 & 85.6 & 59.4 & $600^{\mathrm{b}}$ \\
\hline 0.2 & - & $52-66$ & 110 & 78.0 & 55.6 & 95 \\
\hline 0.2 & - & $52-66$ & 70 & Coagulate & - & - \\
\hline- & 0.2 & $44-66$ & 70 & Coagulate & - & - \\
\hline - & 0.2 & $44-66$ & 72 & 91.1 & 47.0 & 250 \\
\hline - & 0.5 & $44-66$ & 72 & 86.2 & 48.7 & 100 \\
\hline - & 0.5 & $52-66$ & 69 & Coagulate & - & - \\
\hline
\end{tabular}

a Monomer/water ratio, 100/52; Na-rosinate, $1 \mathrm{~g}$; KPS, $0.3 \mathrm{~g} ; n$-DDM, $0.25 \mathrm{~g}$.

b Particle size distribution of marked latex $/ \%$

\begin{tabular}{ccccccc}
\hline $0.1 \mu \mathrm{m}$ under & $0.1-0.2 \mu \mathrm{m}$ & $0.2-0.3 \mu \mathrm{m}$ & $0.3-0.4 \mu \mathrm{m}$ & $0.4-0.8 \mu \mathrm{m}$ & $0.8 \mu \mathrm{m}$ over \\
\hline 22 & 29 & 10 & 16 & 20 & 3 \\
\hline
\end{tabular}

Table II. Effects of the addition of PVME and PVME- $\mathrm{MgSO}_{4}$ on the high solid polymerization ${ }^{\mathrm{a}}$

\begin{tabular}{|c|c|c|c|c|c|c|c|c|c|c|}
\hline \multirow{2}{*}{$\frac{\text { PVME }}{\mathrm{phr}}$} & \multirow{2}{*}{$\frac{\mathrm{MgSO}_{4}}{\mathrm{phr}}$} & \multirow{2}{*}{$\frac{\text { Temp }}{{ }^{\circ} \mathrm{C}}$} & \multirow{2}{*}{$\frac{\text { Time }}{h}$} & \multirow{2}{*}{$\frac{\text { Viscosity }^{\mathrm{b}}}{\mathrm{CP}}$} & \multicolumn{6}{|c|}{ Particle size distribution $/ \%$} \\
\hline & & & & & $\begin{array}{l}0.2 \mu \mathrm{m} \\
\text { under }\end{array}$ & $\begin{array}{c}0.2-0.3 \\
\mu \mathrm{m}\end{array}$ & $\begin{array}{c}0.3-0.4 \\
\mu \mathrm{m}\end{array}$ & $\begin{array}{c}0.4-0.8 \\
\mu \mathrm{m}\end{array}$ & $\begin{array}{c}0.8 \mu \mathrm{m} \\
\text { over }\end{array}$ & \\
\hline- & - & $44-66$ & 70 & ca. 2000 & & & & & & (Viscous latex) \\
\hline - & - & $52-66$ & 72 & - & & & & & & (Coagulation) \\
\hline 0.04 & - & 52 & 41 & 280 & 17 & 17 & 13 & 47 & 6 & Gelation occur \\
\hline 0.01 & - & 52 & 50 & 310 & & & & & & $\begin{array}{l}\text { (Partially paste } \\
\text { polymer formed) }\end{array}$ \\
\hline 0.01 & 0.01 & 52 & 42 & 180 & 10 & 30 & 25 & 29 & 6 & Gelation occur \\
\hline 0.01 & 0.02 & 52 & 47 & 210 & 8 & 30 & 20 & 37 & 5 & Gelation occur \\
\hline
\end{tabular}

${ }^{\text {a }}$ Monomer/water ratio, $100 \mathrm{~g} / 52 \mathrm{~g}$; Na-rosinate, $1 \mathrm{~g}$; KPS, $0.3 \mathrm{~g} ; n$-DDM, $0.25 \mathrm{~g}$.

b Measurement of latices concentrated to $55 \%$ solids.

Concurrent Use of Sodium Alginate and that of 0.001 parts sodium alginate and 0.02 $\mathrm{MgSO}_{4}$

Table III shows the results of the polymerization with the addition of sodium alginate and $\mathrm{MgSO}_{4}$. Gelation and formation of paste polymer as observed on adding of PVME did not occur and reproducibility was very good. The optimum condition was ascertained as parts $\mathrm{MgSO}_{4}$ to 100 parts monomer. Table IV shows that the reproducibility was not affected by the scaling up of the reaction vessel, of 101 , 201,601 , and 17001 . Figure 2a shows typical time-conversion curves. These similar profiles imply that the desired high solid, large particle, polydispersed latices were obtained with good 
Table III. Effects of the addition of sodium alginate- $\mathrm{MgSO}_{4}$ on the high solid polymerization

\begin{tabular}{|c|c|c|c|c|c|c|c|c|c|c|c|c|}
\hline \multirow{2}{*}{$\frac{\text { Sodium alginate }}{\mathrm{phr}}$} & \multirow{2}{*}{$\begin{array}{c}\mathrm{KCl} \\
\mathrm{phr}\end{array}$} & \multirow{2}{*}{$\frac{\mathrm{MgSO}_{4}}{\mathrm{phr}}$} & \multirow{2}{*}{$\frac{\text { Temp }}{{ }^{\circ} \mathrm{C}}$} & \multirow{2}{*}{$\frac{\text { Time }}{\mathrm{h}}$} & \multirow{2}{*}{$\frac{\text { Total solid }}{\%}$} & \multirow{2}{*}{$\frac{\text { Viscosity }}{\mathrm{CP}}$} & \multicolumn{6}{|c|}{ Particle size distribution $/ \%$} \\
\hline & & & & & & & $\begin{array}{c}0.1 \mu \mathrm{m} \\
\text { under }\end{array}$ & $\begin{array}{c}0.1-0.2 \\
\mu \mathrm{m}\end{array}$ & $\begin{array}{c}0.2-0.3 \\
\mu \mathrm{m}\end{array}$ & $\begin{array}{c}0.3-0.4 \\
\mu \mathrm{m}\end{array}$ & $\begin{array}{c}0.4-0.8 \\
\mu \mathrm{m}\end{array}$ & $\begin{array}{c}0.8 \mu \mathrm{m} \\
\text { over }\end{array}$ \\
\hline 0.0005 & - & - & $46-66$ & 68 & 58.8 & 560 & \multicolumn{6}{|c|}{ (Paste polymer formed) } \\
\hline 0.001 & - & - & $46-66$ & 68 & 56.5 & 330 & \multicolumn{6}{|c|}{ (Paste polymer formed) } \\
\hline 0.005 & - & - & $46-66$ & 71 & 55.3 & 270 & \multicolumn{6}{|c|}{ (Paste polymer formed) } \\
\hline 0.001 & 0.1 & - & $46-66$ & 72 & 56.9 & 140 & \multicolumn{6}{|c|}{ (Partially coagulation occur) } \\
\hline 0.001 & 0.2 & - & $46-66$ & 73 & - & - & \multicolumn{6}{|c|}{ (Coagulation occur) } \\
\hline 0.005 & 0.1 & - & $46-66$ & 70 & 60.7 & 1090 & \multicolumn{6}{|c|}{ (Partially paste polymer formed) } \\
\hline 0.001 & - & 0.01 & $46-66$ & 70 & 57.3 & 150 & & & & & & \\
\hline 0.001 & - & 0.01 & $46-66$ & 69 & 59.8 & 500 & 10 & 43 & 20 & 16 & 8 & 1 \\
\hline 0.001 & - & 0.01 & $46-52--66$ & 69 & 58.9 & 300 & 10 & 39 & 26 & 8 & 14 & 3 \\
\hline 0.001 & - & 0.02 & $46-52-66$ & 69 & 58.0 & 130 & & & & & & \\
\hline 0.001 & - & 0.02 & $46-52-66$ & 71 & 57.9 & 100 & 7 & 15 & 38 & 10 & 23 & 7 \\
\hline 0.001 & - & 0.02 & $46-52-66$ & 71 & 58.7 & 70 & 3 & 24 & 33 & 7 & 23 & 10 \\
\hline 0.002 & - & 0.02 & $46-52-66$ & 70 & 56.0 & 190 & \multicolumn{6}{|c|}{ (Partially paste polymer formed) } \\
\hline 0.001 & - & 0.05 & $46-52-66$ & 72 & 55.9 & 140 & \multicolumn{6}{|c|}{ (Partially coagulate) } \\
\hline
\end{tabular}

${ }^{\mathrm{a}}$ Monomer/water ratio, $100 \mathrm{~g} / 52 \mathrm{~g}$; Na-rosinate, $1 \mathrm{~g}$; KPS, $0.3 \mathrm{~g} ; n$-DDM, 0.25 . 
Table IV. Properties of high solid latex manufactured by large scale vessel ${ }^{\mathrm{a}}$

\begin{tabular}{|c|c|c|c|c|c|c|c|c|c|c|c|}
\hline \multirow{2}{*}{$\frac{\begin{array}{c}\text { Reacter } \\
\text { vol }\end{array}}{1}$} & \multirow{2}{*}{$\frac{\text { Time }}{\mathrm{h}}$} & \multirow{2}{*}{$\begin{array}{c}\text { Total } \\
\text { solid }\end{array}$} & \multirow{2}{*}{$\frac{\text { Viscosity }}{\mathrm{CP}}$} & \multirow{2}{*}{$\frac{\begin{array}{c}\text { Gel } \\
\text { content }\end{array}}{\%}$} & \multirow{2}{*}{$\begin{array}{l}\text { Swelling } \\
\text { index }\end{array}$} & \multicolumn{6}{|c|}{ Particle size distribution $/ \%$} \\
\hline & & & & & & $\begin{array}{l}0.1 \mu \mathrm{m} \\
\text { under }\end{array}$ & $\begin{array}{c}0.1-0.2 \\
\mu \mathrm{m}\end{array}$ & $\begin{array}{c}0.2-0.3 \\
\mu \mathrm{m}\end{array}$ & $\begin{array}{c}0.3-0.4 \\
\mu \mathrm{m}\end{array}$ & $\begin{array}{c}0.4-0.8 \\
\mu \mathrm{m}\end{array}$ & $\begin{array}{c}0.8 \mu \mathrm{m} \\
\text { over }\end{array}$ \\
\hline 10 & 72 & 61.9 & 160 & 78 & 12 & 9 & 20 & 40 & 5 & 22 & 4 \\
\hline 20 & 73 & 62.9 & 140 & 83 & 16 & 3 & 24 & 33 & 7 & 23 & 10 \\
\hline 60 & - & 60.0 & 260 & 83 & 13 & 12 & 23 & 27 & 8 & 19 & 12 \\
\hline 1700 & 60 & 60.0 & 190 & 84 & 15 & 2 & 19 & 38 & 8 & 23 & 10 \\
\hline
\end{tabular}

${ }^{a}$ Monomer/water ratio, $100 \mathrm{~g} / 52 \mathrm{~g} ; \mathrm{N}$-rosinate, $1 \mathrm{~g}$; KPS, $0.3 \mathrm{~g} ; n$-DDM, $0.25 \mathrm{~g} ; \mathrm{Na}$-alginate, $0.001 \mathrm{~g} ; \mathrm{MgSO}_{4}, 0.02 \mathrm{~g}$. Temp condition $=101,201$, and $601,46 \rightarrow 52 \rightarrow 66^{\circ} \mathrm{C} ; 17001,52 \rightarrow 66^{\circ} \mathrm{C}$.

reproducibility.

Figure $2 \mathrm{~b}$ shows the rate of the polymerization calculated from the curve (2) in Figure 2a. This figure also shows the change of the number of polymer particles, observed by electron microscope of aliquot hourly taken out (small particles produced by the addition of the booster solution were excluded). The electron micrographs (Figures $3 \mathrm{a}-\mathrm{d}$ ) of the particles in aliquots taken at 10, 20,30, and 40\% conversion also show the change in particle diameter.

For mutual polymerizations, the rate of reaction, $R_{\mathrm{p}}$, is defined by the following eq 1 ,

$$
R_{\mathrm{p}}=K_{\mathrm{p}} \cdot r \cdot M \cdot N
$$

where $K_{\mathrm{p}}$ denotes the propagation rate constant, $r$ the average number of free-radicals in each particles, $M$ the monomer concentration in a particle and $N$ the number of particles. Generally, $R_{\mathrm{p}}$ increases in the initial stage (1st stage) where the number of particles is increasing, and reaches the stationary state $\left(R_{\mathrm{p}}=\right.$ constant) where the number of particles is constant. This stage is called a 0 order reaction zone (2nd stage) proposed by Omi et al. ${ }^{17}$ However the present high-solid polymerization did not have the 2 nd stage, the region where $R_{\mathrm{p}}=$ constant. $R_{\mathrm{p}}$ begins to decline almost instantly due to the decrease of the number of the particles by particle agglomeration after the 1st stage. A direct observation through the sight window of the reaction vessel

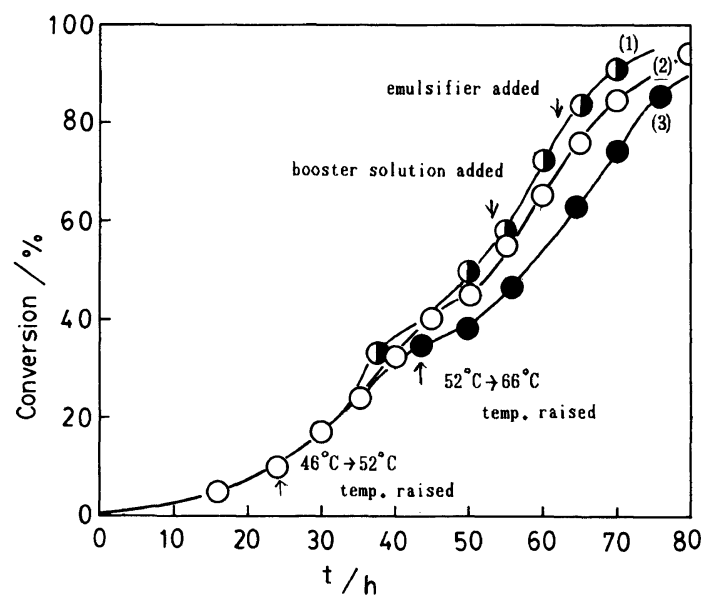

Figure 2a. Time-conversion curves in the case of agglomeration promoter $\left(\mathrm{Na}\right.$ alginate $\& \mathrm{MgSO}_{4}$ ) addition. Butadiene, $100 \mathrm{~g}$; water, $52 \mathrm{~g}$; Na-rosinate, $1 \mathrm{~g}$; KPS, $0.3 \mathrm{~g} ; n$-DDM, $0.25 \mathrm{~g}$; Na-alginate, $0.001 \mathrm{~g} ; \mathrm{MgSO}_{4}$, $0.02 \mathrm{~g}$; temp $=46^{\circ} \mathrm{C}, 52^{\circ} \mathrm{C}, 66^{\circ} \mathrm{C}$. Impeller speed $(1700 \mathrm{l}$ vessel): (1) $100 \mathrm{rpm}$; (2) $\bigcirc, 120 \mathrm{rpm}$; (3) O, $140 \mathrm{rpm}$.

indicated that the viscosity of the polymerization system begins to decrease at this stage. This fact also supports the above-mentioned consideration of particle agglomeration.

Even if the polymerization temperature was raised at this stage, the rate was not necessarily increased. This fall-off in the rate was considered a decrease in the concentration of living radicals. To keep the polymerization rate high, a booster solution was added. $R_{\mathrm{p}}$ was increased again, showing the onset of a new emulsion polymerization. Finally, the 


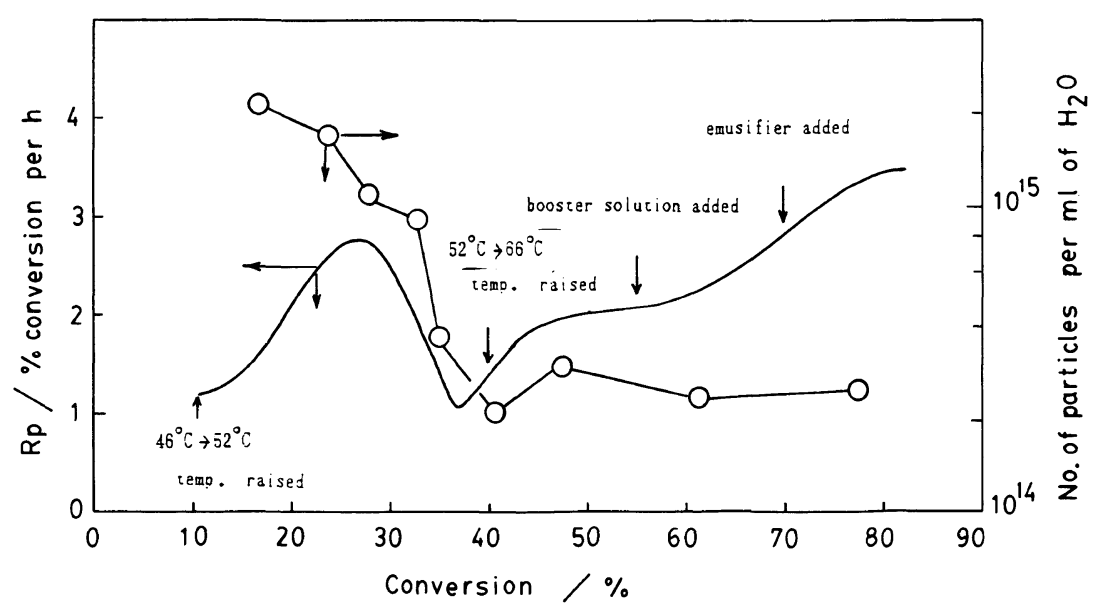

Figure 2b. Dependence on conversion of $R_{\mathrm{p}}$ and number of particles in the high solid polymerization. Curve (a) was obtained by the calculation from curve (2) in Figure 2a and curve (b) was obtained from the photographs of the particles in aliquots taken at each conversion.

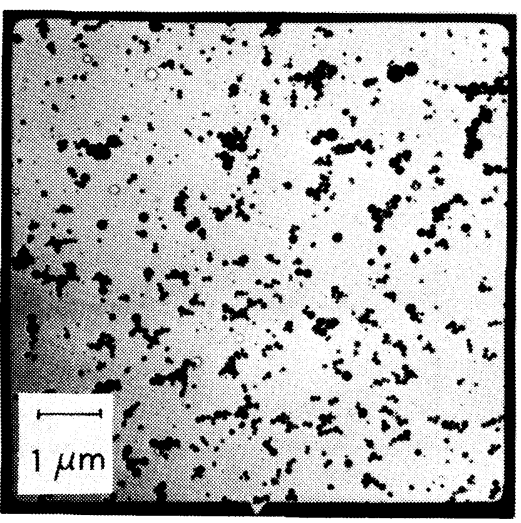

(a)

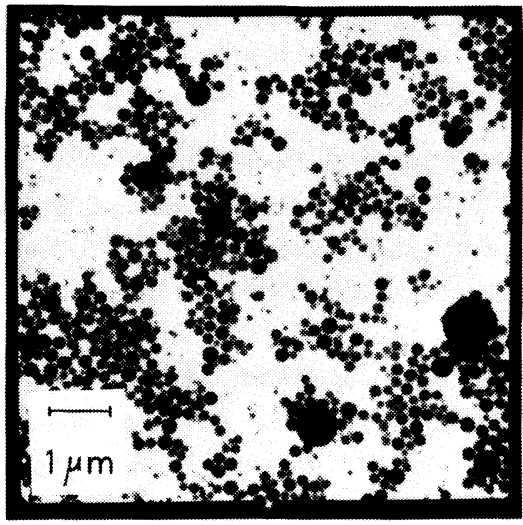

(c)

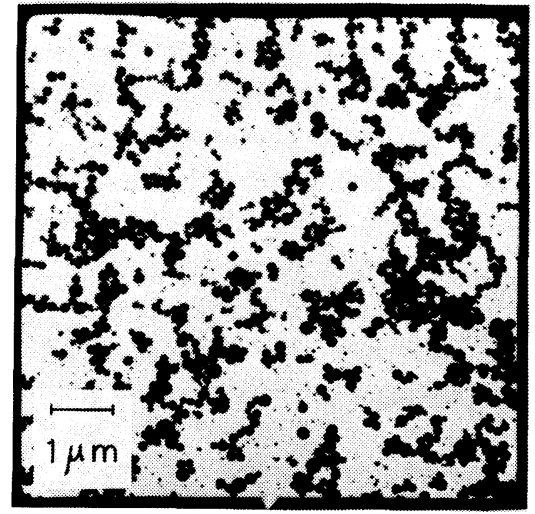

(b)

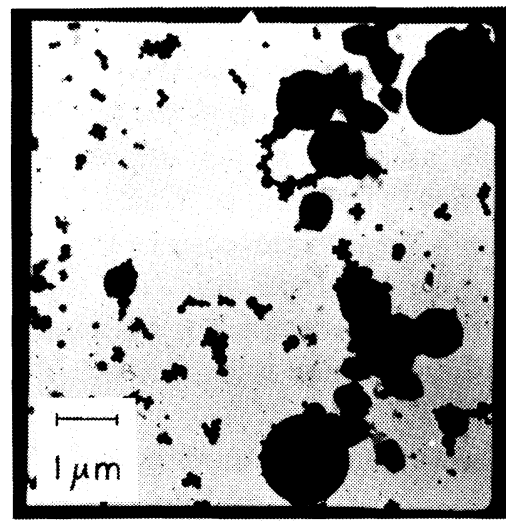

(d)

Figure 3. Electron micrographs of particles in aliquots taken at: (a) $10 \%$ conversion; (b) $20 \%$ conversion; (c) $30 \%$ conversion; (d) $40 \%$ conversion. 
concentration of monomer in the polymer particles decreased, and the polymerization rate gradually fell off. In this manner, the conversion reached about $90 \%$ or above and, thus polydispersed high solid latices were obtained.

In general, a water soluble polymer is adsorbed on the latex particles, ${ }^{18,19}$ and controls hydration $^{20}$ and interaction of the particles. ${ }^{21}$ In the present study, it is thought that the coalescence of polymer particles was controlled by water soluble magnesium alginate and the agglomeration proceeded very smoothly. Figure 4 shows its speculated model. Though the specificity of magnesium alginate is not clearly explained, a half molar amount of $\mathrm{MgSO}_{4}$ to the sodium alginate is the most effective. This means that magnesium alginate acts on the electric double layer film ${ }^{22}$ of the present polymer particles covered with emulsifier and coalescence them effectively.

It appears to that the water-soluble magnesium alginate reacts with the emulsifier which covers the polymer particle and spills out the emulsifier with aid of magnesium ions in the alginate and then the alginate is adsorbed on the particles and aggregates with them.

\section{Effects of the Booster Solution}

The addition of booster solution in the final stage of the reaction, which generates small particles, reduces the fall-off in the rate of polymerization due to the drop in the number of the particles, and also makes the particle concentration high. The presence of small particles is essentially disadvantageous to the following graft polymerization for ABS resin synthesis. ${ }^{23}$ Thus, the best time for examining is when the booster solution is charged into the reaction mixture.

Figure 5 shows the relation between the generation of small particles and the charging time of the booster solution.

It is reported that there is no free monomer remaining when the conversion reaches $50 \%$ in

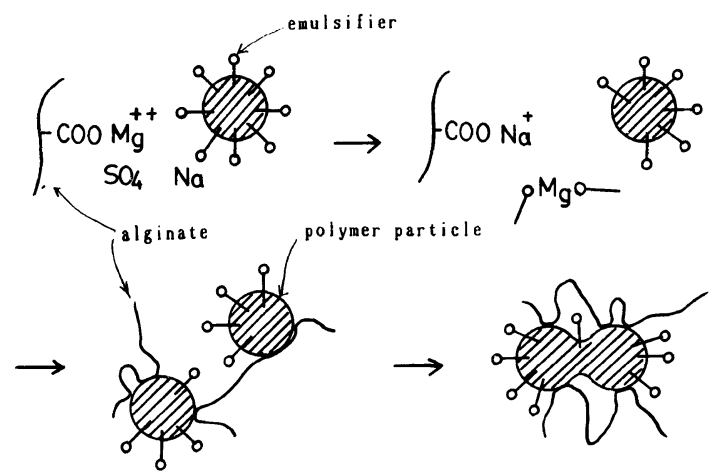

Figure 4. Action of magnesium alginate on the coalescence of polymer particles covered with emulsifier.

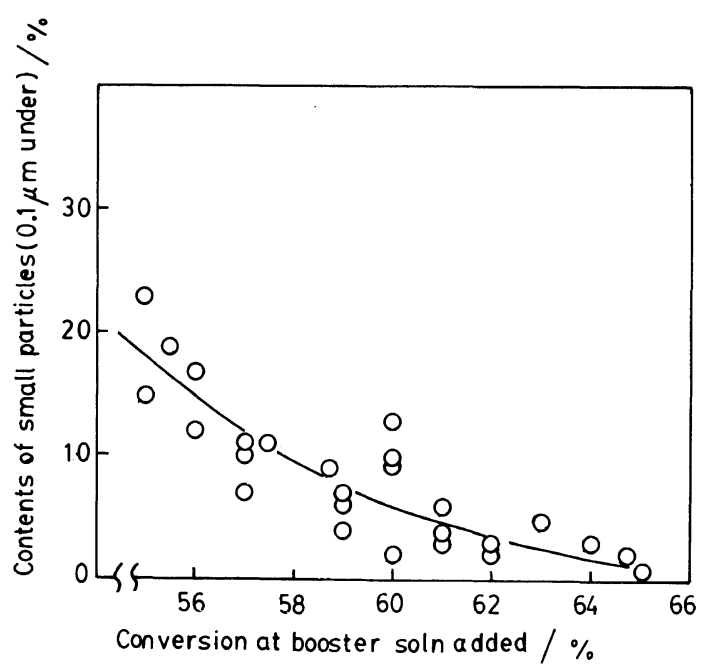

Figure 5. Relation between conversion on adding the booster solution and the content of small particles in the high solid latex obtained.

the emulsion polymerization of butadiene. ${ }^{24}$ The newly produced particles generated by the addition of the booster solution are formed by the polymerization of monomer eluted out from the large polymer particles existing already in the system. Figure 5 shows that the quantity of small particles produced by the addition of the booster solution decreases with the time of addition. This means that the number of newly produced particles is related to the amount of the monomer eluted out from the particles. 
In conclusion, by the addition of the new agglomeration promoters, the combination of sodium alginate and $\mathrm{MgSO}_{4}$, under precise reaction control, the direct manufacturing process of a high solid, polydispersed polybutadiene latex of large particle size with excellent reproducibility is possible.

Acknowledgements. The author would like to express his appreciation to Dr. M. Takahashi and Mr. H. Hayashi for their helpful discussion and to Mr. K. Kuroda, Mr. S. Iwai, Mr. H. Satoh, and Mr. T. Kiyota for their support and help with this work.

\section{REFERENCES}

1. "ABS Jushi," Kobunshi Kikai Zairyou Iinkai, Japan, Ed., Kobunshi Gakkai, Tokyo, 1970, p 21.

2. W. J. Frazer, Chem. Ind. (London), No. 33, Aug. 13, 1399 (1966).

3. K. Arakawa and H. Nagai, Kobunshi Ronbunshu, 33, 70 (1976).

4. M. S. Thompson, U. S. Patent 3111501 (Dec. 19, 1958).

5. L. H. Howland and R. W. Brown, Rubber Chem. Technol., 34, 1501 (1961).

6. F. D. Chittenden, C. D. McCleary, and H. S. Smith,
Ind. Eng. Chem., 40, 337 (1948).

7. A. M. Borders and R. M. Pierson, Ind. Eng. Chem., 40, 1473 (1948).

8. L. H. Howland, "Synthetic Rubber," G. S. Whitby, Ed., John Wiley \& Sons, Inc., New York, N. Y., 1954, pp 649-667.

9. J. P. McKenzie, Rubber Age, Aug. 814 (1957).

10. L. H. Howland, E. J. Aleska, R. W. Brown, and E. L. Borg, Rubber Plast. Age, 42, 868 (1961).

11. W. E. Brown, J. Appl. Phys., 18, 273 (1948).

12. E. Schmidt and P. H. Biddison, Rubber Chem. Technol., 34, 433 (1961).

13. W. H. Pahl, Chem. Eng. Prog., 43, 515 (1947).

14. S. Nagata, K. Yamamoto, and M. Ujihara, Kagaku Kōgaku, 23, 180 (1947)

15. F. D. Chittenden, C. D. McCleary and H. S. Smith, India Rubber World, 113, 809 (1946).

16. P. H. Johnson and R. H. Kelsey, Rubber World, Sept., 877 (1958).

17. S. Omi and H. Kubota, Asahi Garasu Kogyo Gijutsu Shorei-kai Kenkyu Hokoku (Japan), 13, 267 (1967).

18. T. Matsumoto, K. Nakamae, K. Nonaka, and T. Uehara, Kobunshi Ronbunshu, 31, 508 (1974).

19. F. Kitahara and K. Furusawa, "Bunsan Nyuuka Kei no Kagaku,” Kogaku Tosho K. K., Tokyo, 1979.

20. C. F. Fryling, J. Colloid Sci., 18, 713 (1965).

21. F. L. Saunders and J. W. Sanders, J. Colloid Sci., 11, 260 (1956).

22. J. G. Brodnyan and E. L. Kelley, J. Colloid Sci., 20, 7 (1965).

23. N. Yamauchi, private communication.

24. E. J. Meehan, J. Am. Chem. Soc., 71, 628 (1949). 